\title{
ARTICLE OPEN \\ Feasibility and effectiveness of an Asthma/COPD service for primary care: a cross-sectional baseline description and longitudinal results
}

\author{
Esther I Metting ${ }^{1,2}$, Roland A Riemersma ${ }^{1,2}$, Janwillem H Kocks ${ }^{1,2}$, Margriet G Piersma-Wichers ${ }^{3}$, Robbert Sanderman ${ }^{4,5}$ \\ and Thys van der Molen ${ }^{1,2}$
}

\begin{abstract}
BACKGROUND: In 2007, an Asthma/chronic obstructive pulmonary disease (COPD) (AC) service was implemented in the North of the Netherlands to support General Practitioners (GPs) by providing advice from pulmonologists on a systematic basis.

AIMS: To evaluate the feasibility and effectiveness of this service on patient-related outcomes.

METHODS: We report baseline data on 11,401 patients and follow-up data from 2,556 patients. GPs can refer all patients with possible obstructive airway disease (OAD) to the service, which is conducted by the local laboratory. Patients are assessed in the laboratory using questionnaires and spirometry. Pulmonologists inspect the data through the internet and send the GP diagnosis and management advice.

RESULTS: A total of 11,401 patients were assessed by the service, covering almost $60 \%$ of all adult patients with projected asthma or COPD in the area. In all, $46 \%(n=5,268)$ of the patients were diagnosed with asthma, $18 \%(n=2,019)$ with COPD and $7 \%(n=788)$ with the overlap syndrome. A total of $740(7 \%)$ patients were followed up after 3 months because the GP advised them to change medication. In this group, the proportion of unstable COPD patients (Clinical COPD Questionnaire (CCQ) $\geqslant 1$ ) decreased from 63\% $(n=92)$ at baseline to $49 \%(n=72)$. The proportion of patients with uncontrolled asthma (Asthma Control Questionnaire $(A C Q) \geqslant 1.5)$ decreased from $41 \%(n=204)$ to $23 \%(n=115)$. In all, $938(8 \%)$ patients were followed up after 12 months. From these patients, the proportion of unstable COPD patients (CCQ $\geqslant 1)$ decreased from $47 \%(n=115)$ to $44 \%(n=107)$. The proportion of patients with uncontrolled asthma (ACQ $\geqslant 1.5)$ decreased from $16 \%(n=95)$ to $14 \%(n=85)$.

CONCLUSION: The AC service assessed a considerable proportion of patients with OAD in the area, improved patients' outcomes, and is considered to be feasible and effective.
\end{abstract}

npj Primary Care Respiratory Medicine (2015) 25, 14101; doi:10.1038/npjpcrm.2014.101; published online 8 January 2015

\section{INTRODUCTION}

Asthma and chronic obstructive pulmonary disease(COPD) are prevalent chronic diseases in the community. ${ }^{1}$ In the Netherlands, 60 to $80 \%$ of all asthma and COPD patients are treated by their general practitioner (GP), and patients are only referred to the pulmonologist in case of severe uncontrolled asthma or severe COPD. ${ }^{2}$ Misdiagnosis and underdiagnosis are common, ${ }^{3-5}$ as asthma and COPD overlap in symptoms, whereas their treatments are different. ${ }^{6}$ Some patients have both asthma and COPD, the socalled overlap syndrome, which can be described as (partly) reversible but progressive deterioration in lung function, often combined with a history of smoking and previous diagnosis of asthma and/or allergies. These diagnostic problems may lead to suboptimal treatment, whereas early correct treatment can reduce costs, morbidity and mortality, can improve symptoms and enhance patient outcomes. ${ }^{3-5,7}$

In daily clinical practice, many GPs often lack the knowledge, time and enthusiasm to perform all tasks that are recommended by guidelines. For example, Dutch GPs are obliged to follow 96 guidelines for common diseases, of which only three are concerned with asthma, asthma in children, and COPD. ${ }^{8-10} \mathrm{GPs}$ therefore could benefit from the knowledge and experience of pulmonologists by obtaining advice for each patient with pulmonary symptoms. Cooperation between GPs and other caregivers in integrated care projects for COPD patients has been proven to be effective in improving the quality of life and health status of patients, thus reducing costs and the number of hospitalisations. ${ }^{11,12}$ Asthma/COPD services in which GPs are supported by pulmonologists in interpreting spirometry results are feasible and might improve diagnostic accuracy. ${ }^{13}$ GPs and pulmonologists in the North of the Netherlands collaborated and implemented the Asthma/COPD (AC) service in 2007 as a support service for GPs. The aim of this service is to improve the management of asthma and COPD patients in primary care. Although the service was not developed for scientific reasons, data from included patients are available for research. This paper describes the development and feasibility of this service, the patient population and its effect on patient-related outcomes.

\footnotetext{
${ }^{1}$ Department of General Practice, University of Groningen, University Medical Center Groningen, Groningen, The Netherlands; ${ }^{2}$ GRIAC Research Institute Groningen, University of Groningen, University Medical Center Groningen, Groningen, The Netherlands; ${ }^{3}$ Certe Laboratories, Groningen, The Netherlands; ${ }^{4}$ Department of Health Psychology, University of Groningen, University Medical Center Groningen, Groningen, The Netherlands and ${ }^{5}$ Department of Psychology, Health and Technology, University of Twente, Enschede, The Netherlands.

Correspondence: El Metting (E.I.Metting@umcg.nl)

Received 3 June 2014; revised 26 August 2014; accepted 5 October 2014
} 


\section{MATERIALS AND METHODS}

\section{Design and feasibility}

Meetings with local physicians were organised, resulting in four starting principles: (1) the service should optimise diagnosis, treatment and management; (2) the GP is in lead; (3) the service should be easily accessible for patients and physicians; (4) allocation of tasks between primary and secondary care have to be defined clearly. ${ }^{14}$ Yearly meetings are organised to inform physicians about current developments, discuss casuistry and enhance commitment.

The role of the GP. GPs can refer individual patients ( $\geqslant 8$ years of age) who are suspected to have asthma, COPD, overlap syndrome or present with pulmonary symptoms of unknown origin further referred to as obstructive airway disease (OAD). The GP can also choose to refer all OAD patients in his/her practice on the basis of inhaled medication use and/or courses of prednisolone. When preferred by the GP, referral may also include followup assessments by the AC service. Finally, the GP decides what to do with the advice of the pulmonologist and is responsible for the disease management.

Self-reported information by patients. Patients complete the 'Asthma Control Questionnaire (ACQ),' the 'Clinical COPD Questionnaire (CCQ)' and a medical history questionnaire assessing gender, age, age of onset, family history, symptoms, exacerbations (having used oral corticosteroids or antibiotics for lung problems), allergy and other stimuli-provoking symptoms, medication, occupation and smoking history as part of the regular assessment procedure.

The ACQ is used to measure asthma control and contains six questions (range 0-6), and the total score can be divided into 'controlled' $(<0.75)$, 'partially controlled' (0.75-1.50) and 'uncontrolled' ( $\geqslant 1.50) .{ }^{14}$ The CCQ is used to measure COPD health status, and it contains 10 questions. The total score (range $0-6)$ can be distributed between 'stable' $(<1)$, 'not entirely stable', ',2 'unstable' ${ }^{2,3}$ and 'very unstable' $(\geqslant 3)$. This questionnaire contains three subdomains with four questions about functional status, four questions about symptoms and two questions about mental status. $^{14,15}$

Assessment by the trained lung function technician. The assessments take place in local laboratories according to a strict protocol. The following measurements are taken:

- Body mass index.

- Evaluation and, if needed, instruction of the inhalation technique according to the Dutch 'Inhalation Medication Instruction School' guidelines.

- Spirometry according to international guidelines. ${ }^{16}$

All data, including the scores on the questionnaires, are inserted in an Electronic Diagnostic Support (EDS) system.

The role of the pulmonologist. Pulmonologists are trained in using the service by following at least two training sessions. In this paper, we included pulmonologists who had assessed $\geqslant 300$ patients to avoid the influence of learning effects. Pulmonologists assess the quality of the spirometry, inspect all outcomes in the Electronic Diagnostic Support system and make a report (based on current international guidelines ${ }^{2,17}$ ) with diagnosis, follow-up and treatment advice. Treatment advice can include lifestyle advice (e.g., dietician, smoking cessation or physical activity) or medication change. Pulmonologists were not provided with strict diagnostic rules. The GPs receive the report from the pulmonologist within 5 working days through the internet directly in their patient information system.

\section{Statistical data analyses}

IBM-SPSS version 22 was used for statistical analysis. The baseline population was described by age, gender, body mass index, exacerbation history, smoking history, lung function performances, diagnosis and GOLD 2013 category (A, B, C and D). ${ }^{17}$ A positive bronchodilator response was defined as an increase in forced expiratory volume in $1 \mathrm{~s}\left(\mathrm{FEV}_{1}\right)$ of $\geqslant 12 \%$ and $\geqslant 200 \mathrm{ml}$. The median scores of GOLD A, B, C and D patients on the CCQ subscales are presented.
Feasibility analyses. Feasibility was assessed by analysing the following: (1) the proportion of GPs in the target area who used the AC service between 2007 and 2012; (2) the proportion of patients with asthma or COPD who were assessed by the service in the target area since $2007: i^{18}$ (3) the quality of the spirometry; (4) the number of patients that could be diagnosed, and the variation in diagnostic pattern between the different pulmonologists by using chi-square.

Follow-up visits. Patients for whom medication change was advised by the pulmonologist were automatically scheduled for an additional followup assessment after 3 months (range 2-4 months, $n=740$ ). If the GP requested follow-up visits and no medication change was advised, patients were assessed after 12 months (range 10-14, $n=938$ ). Baseline data of adult patients on exacerbations/year, smoking status, inhalation technique, ACQ and CCQ scores were compared with follow-up data. Nonparametric paired tests were used to compare baseline data with follow-up data Paired $t$-tests were used for the longitudinal evaluation of $\mathrm{FEV}_{1}$ (in litres). Follow-up data of baseline GOLD stages are presented to show the distribution of these patients to other GOLD stages. ${ }^{17}$ To prevent overlap in our results, we excluded patients with $>1$ follow-up assessment in 1 year $(n=79)$.

\section{RESULTS}

Baseline patient characteristics are presented in Tables 1 and 2 .

\section{Feasibility}

The service included around 2,000 (range: 1,813-2,109) new patients yearly from $79.3 \%$ of the GPs in the target area. Approximately $50 \%$ of patients were included by practice screening. In all, $60 \%$ of all adult asthma and COPD patients in the target area were assessed at least once by the AC service. ${ }^{18,19}$ Pulmonologists considered the quality of $93.6 \%$ of the spirometry graphs to be usable for diagnosis and could diagnose $79.4 \%$ of the patients (asthma: $45.8 \%$, COPD: $17.8 \%$, overlap syndrome: $6.9 \%$ ). See Supplementary 1 for an overview of COPD GOLD A, B, C and D patients at baseline. Baseline diagnosis was compared with followup diagnosis, and it did not change during the follow-up in $91.2 \%$ (confidence interval: $89.4-92.7 \%$ ) of baseline asthma patients, in 87.7\% (confidence interval: $84.4-90.4 \%$ ) of baseline COPD patients and in $74.2 \%$ (confidence interval: $68.0-79.5 \%$ ) of baseline overlap syndrome patients. There was variation in diagnostic pattern in adult patients between the different pulmonologists $(n=10$, $P<0.000)$; see Figure 1 .

\section{Follow-up visits}

Patients frequently changed from GOLD (2013) category, and many GOLD D patients $(n=74)$ moved to other GOLD categories at follow-up (Follow-up category: GOLD A: $21.6 \%$, B: $36.5 \%$, C: $6.8 \%$, D: $35.1 \%)$; see Figure 2.

Patients advised to change medication (Patients followed-up after 3 months, total=740). Inhalation technique improved significantly (correct at baseline $35.1 \%$ to $52.5 \%$ after 3 months, $n$ total $=459$, $P<0.000)$. The proportion of well-controlled asthma patients increased from $23.9 \%$ (baseline) to $49.5 \%$ ( 3 months, $n$ total $=487$ $P<0.000)$, and the proportion of stable COPD patients increased from $27.4 \%$ (baseline) to $48.9 \%$ (3 months, $n$ total $=145, P=0.004$ ). The proportion of GOLD D patients decreased from $12.8 \%$ at baseline to $6.7 \%$ after 3 months; see Table 3 ( $n$ total $=145$, $P<0.000)$.

Patients advised to continue current medication (Patients followedup after 12 months, $n=938$ ). Inhalation technique did improve significantly (correct baseline 37.4 to $49.9 \%$ after 12 months, $n=741, P<0.000)$. The proportion of current smokers decreased from $25.2 \%$ at baseline to $23.2 \%$ after 12 months $(n=984$, $P=0.013)$. The proportion of asthma and COPD patients with $\geqslant 1$ 
Table 1. Baseline characteristics of the total patient population in the $A C$ tele-medicine service

\begin{tabular}{|c|c|}
\hline Variable & Total group, $\mathrm{n}=11,401$ \\
\hline Diagnosis of & $n(\%)$ \\
\hline COPD & $2,031(17.8)$ \\
\hline Very unstable $(C C Q \geqslant 3)$ & $161(8.0)$ \\
\hline Asthma & $5,223(45.8)$ \\
\hline Uncontrolled $(A C Q \geqslant 1.50)$ & $2,049(39.3)$ \\
\hline Asthma/COPD overlap syndrome & 787 (6.9) \\
\hline Very unstable $(C C Q \geqslant 3)$ & 77 (9.9) \\
\hline Uncontrolled $(A C Q \geqslant 1.50)$ & $308(39.4)$ \\
\hline Indication for restriction & $159(1.4)$ \\
\hline No lung disease & $796(7.0)$ \\
\hline Unclear diagnosis & 2,354 (20.6) \\
\hline Missing at random & $15(0.1)$ \\
\hline Diagnosis is unclear because of & $n(\%)$ \\
\hline Incorrect lung function test & $297(12.6)$ \\
\hline Unknown & $2,057(87.4)$ \\
\hline Referral to pulmonologist because of & $n(\%)$ \\
\hline Unclear diagnosis & $1,966(54.7)$ \\
\hline Indication of restriction & $18(0.005)$ \\
\hline Unable to perform lung function test & $18(0.005)$ \\
\hline COPD & $558(15.5)$ \\
\hline $\mathrm{FEV}_{1}<50 \%$ predicted & $302(54.3)$ \\
\hline Asthma/COPD overlap syndrome & $214(6.0)$ \\
\hline $\mathrm{FEV}_{1}<50 \%$ predicted & $27(12.7)$ \\
\hline Asthma & $690(19.2)$ \\
\hline Unstable $(A C Q \geqslant 1.50)$ & $469(68.2)$ \\
\hline Total & $3,593(31.5)$ \\
\hline Quality lung function test & $n(\%)$ \\
\hline Sufficient & $10,670(93.6)$ \\
\hline Insufficient & $730(6.4)$ \\
\hline \multicolumn{2}{|c|}{$\begin{array}{l}\text { In } 31.5 \% \text { of the assessments, the pulmonologist advised the GP to refer } \\
\text { their patient to secondary care mostly because of unclear diagnosis } \\
(54.7 \%) \text {. Most patients with unclear diagnosis (age, } 51 \pm 19 ; \text { age of onset, } \\
\left.39 \pm 23 ; 42 \% \text { male) had no obstruction ( } F E V_{1} / F V C \geqslant 70 \%: 90 \%\right) \text {, no positive } \\
\text { bronchodilator response ( } 93 \%) \text { and no allergy }(76 \%) \text {. However, these } \\
\text { patients were high in symptoms (CCQ } \geqslant 1: 68 \%) \text {. } \\
\text { Abbreviations: AC, asthma/COPD; ACQ, Asthma Control Questionnaire; } \\
C C Q \text {, Clinical COPD Questionnaire; COPD, chronic obstructive pulmonary } \\
\text { disease; } F E V_{1} \text {, forced expiratory volume in one second; FVC, forced vital } \\
\text { capacity; } G P \text {, general practitioner. }\end{array}$} \\
\hline
\end{tabular}

exacerbation last year decreased (asthma: 35.0\% at baseline, $25.2 \%$ at 12 months, $P>0.000$; COPD: $34.8 \%$ at baseline, $25.4 \%$ at 12 months, $P=0.010)$; see Table 4 .

\section{DISCUSSION}

Main findings

In this study, we have evaluated over 11,000 patients referred by 360 different GPs to the Asthma/COPD (AC) service in the North of the Netherlands. With $60 \%$ of all asthma and COPD patients in the area participating, the service is well implemented in the target area. We chose to report the follow-up results from patients who were advised to change medication after 3 months separately from the patients who were advised to continue with their medication and were scheduled to have a 12-month follow-up. If a change in medication was advised, after 3 months, health status improved in COPD patients and asthma control improved in asthma patients. Asthma and COPD patients who did not need medication change and were referred to the yearly follow-up assessment stabilised in asthma control and in COPD health status. Overlap syndrome patients in this group improved in asthma control and health status. Most (65\%) of the GOLD D
Table 2. Baseline characteristics of the patient population per diagnosis

\begin{tabular}{|c|c|c|c|}
\hline Variable & $\begin{array}{c}C O P D \\
\mathrm{n}=2,031\end{array}$ & $\begin{array}{c}\text { Overlap } \\
\text { syndrome, } \\
\mathrm{n}=787\end{array}$ & $\begin{array}{l}\text { Asthma, } \\
\mathrm{n}=5,223\end{array}$ \\
\hline Gender and age & $n(\%)$ & $n(\%)$ & $n(\%)$ \\
\hline Male & $1,190(58.6)$ & $388(49.3)$ & $2,007(38.4)$ \\
\hline \multirow[t]{2}{*}{$\begin{array}{l}\text { Self-reported } \geqslant 1 \\
\text { allergy }\end{array}$} & $243(12.0)$ & $312(39.6)$ & $2,658(50.9)$ \\
\hline & Mean (s.d.) & Mean (s.d.) & Mean (s.d.) \\
\hline Age, years & $66.6(10.8)$ & $60.6(12.3)$ & $43.6(18.7)$ \\
\hline Age of onset, years & $52.2(19.6)$ & $33.6(23.1)$ & $22.3(19.6)$ \\
\hline $\begin{array}{l}\text { Body mass index }(\mathrm{kg} / \\
\left.\mathrm{m}^{2}\right)\end{array}$ & $26.6(4.8)$ & $27.1(4.9)$ & $26.7(6.0)$ \\
\hline $\begin{array}{l}\text { Exacerbations in the } \\
\text { last } 12 \text { months }\end{array}$ & $0.7(1.1)$ & $0.9(1.2)$ & $0.8(1.2)$ \\
\hline \multicolumn{4}{|c|}{ Lung function post bronchodilator, mean (s.d.) } \\
\hline $\mathrm{FEV}_{1}(\mathrm{~L})$ & $2.0(0.7)$ & $2.3(0.7)$ & $3.1(0.9)$ \\
\hline $\mathrm{FEV}_{1} \%$ predicted & $69.0(18.1)$ & $76.0(15.5)$ & $94.6(15.1)$ \\
\hline FVC (L) & $3.6(1.0)$ & $3.7(1.1)$ & $4.0(1.1)$ \\
\hline FVC $\%$ predicted & $98.6(18.4)$ & $102.1(17.2)$ & $101.1(16.3)$ \\
\hline $\mathrm{FEV}_{1} / \mathrm{FVC}$ & $56.0(11.2)$ & $61.0(9.5)$ & $79.3(8.8)$ \\
\hline Reversibility $^{a}$ & $6.4(7.9)$ & $11.2(10.0)$ & $6.7(7.6)$ \\
\hline \multicolumn{4}{|l|}{ Positive $B D T^{b}$ adults, $\mathrm{n}(\%)$} \\
\hline Post $\mathrm{FEV}_{1} / \mathrm{FVC}<70 \%$ & $198(99.0)$ & $236(91.5)$ & $204(25.0)^{c}$ \\
\hline $\begin{array}{l}\text { Post FEV } \\
\text { FVC }=70-80 \%\end{array}$ & $2(1.0)$ & $22(8.5)$ & $358(43.8)$ \\
\hline $\begin{array}{l}\text { Post FEV }{ }_{1} / \\
\text { FVC }=80-90 \%\end{array}$ & & & $214(26.2)$ \\
\hline Post $\mathrm{FEV}_{1} / \mathrm{FVC} \geqslant 90 \%$ & & & $40(4.9)$ \\
\hline Total & $200(10.7)$ & $258(34.8)$ & $817(16.6)$ \\
\hline \multicolumn{4}{|l|}{ Inhalation technique ${ }^{a}, \mathrm{n}(\%)$} \\
\hline Correct & $325(36.1)$ & $205(36.5)$ & $1,434(38.0)$ \\
\hline Incorrect & $576(63.9)$ & $357(63.5)$ & $2,339(62.0)$ \\
\hline \multicolumn{4}{|c|}{ Smoking history (age $\geqslant 18$ years), $\mathrm{n}(\%)$} \\
\hline $\begin{array}{l}\text { Smoking history } \\
\text { missing }\end{array}$ & $8(0.4)$ & $0(0.0)$ & $17(0.4)$ \\
\hline Never smoked & $70(3.4)$ & $54(6.9)$ & $2,041(43.4)$ \\
\hline Quit $\geqslant 12$ months ago & $948(46.7)$ & $378(48.0)$ & 1,628 (34.6) \\
\hline Current smoker & $1,005(49.5)$ & $355(45.1)$ & $1,014(21.6)$ \\
\hline Males & $517(51.4)$ & $151(42.5)$ & $383(37.8)$ \\
\hline $\begin{array}{l}\text { Males motivated to } \\
\text { quit }\end{array}$ & $304(58.8)$ & $89(58.9)$ & $231(60.3)$ \\
\hline Females & $475(47.3)$ & $197(55.5)$ & $614(60.6)$ \\
\hline $\begin{array}{l}\text { Females motivated } \\
\text { to quit }\end{array}$ & $295(62.1)$ & $112(56.8)$ & 407 (66.3) \\
\hline
\end{tabular}

Abbreviations: BDT, bronchodilator test; COPD, chronic obstructive pulmonary disease; $\mathrm{FEV}_{1}$, forced expiratory volume in one second; FVC, forced vital capacity.

${ }^{\mathrm{a}}$ Increase in $\mathrm{FEV}_{1}$ pre bronchodilator compared with $\mathrm{FEV}_{1}$ post bronchodilator.

${ }^{\mathrm{b}}$ Positive bronchodilator response test defined as a reversible lung function of $\geqslant 200 \mathrm{ml}$ and $\geqslant 12 \%$ increase in $\mathrm{FEV}_{1}$ pre bronchodilator compared with $\mathrm{FEV}_{1}$ post bronchodilator.

${ }^{c}$ Adult asthma patients (male: 59\%, mean age: 52 years, 19\% current smokers) with obstruction before and after bronchodilator.

patients moved to other categories after baseline visit; some of these patients (22\%) even improved to GOLD category A. Given these results, we consider the $A C$ service to be a feasible and effective collaboration service for primary and secondary care.

Interpretation of findings in relation to previously published work According to the Global Initiative for Asthma guidelines, uncontrolled asthma patients would be eligible for referral to 
secondary care. ${ }^{2}$ The prevalence of uncontrolled asthma patients in our population (age $\geqslant 16$ years) is lower $(40 \%)$ than the prevalence found in the INSPIRE study where $51 \%$ of the patients had uncontrolled asthma. ${ }^{20}$ Only $13 \%$ of our asthma patients were advised to be referred to secondary care (see Table 1), meaning that the pulmonologists did not follow the Global Initiative for Asthma guidelines. However, we do not know whether the GP followed the referral recommendation of the pulmonologist.

The accuracy of the diagnosis in Asthma/COPD support systems is of pivotal importance. Lucas et al. showed previously that a diagnosis based on paper patient data without life contact in an AC service is comparable with diagnoses acquired by a face-toface consultation. The level of agreement on diagnoses between paper data and face-to-face diagnoses was $\mathrm{K}=0.82,{ }^{21}$ which exceeded the level of inter-doctor agreement from the different assessing pulmonologists $\left(\mathrm{K}=0.64^{22}\right)$. We used comparable history questions and spirometry as Lucas et al. used, and we assume that the diagnostic accuracy will be comparable as in the study of

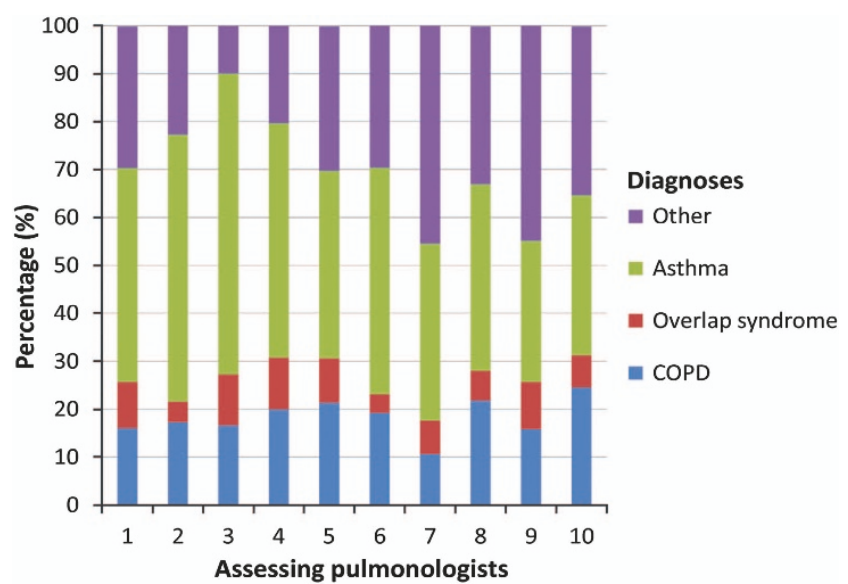

Figure 1. This picture shows the variation in diagnoses in adult patients between the assessing pulmonologists. Most variation is seen in the diagnoses of asthma and other (unclear diagnoses, indication for restriction or no disease). The variation in diagnoses between the pulmonologists was significant (Chi-square $=580$, $n=10,656, P<0.000$ ).
Lucas et al. Diagnoses during follow-up visits in our AC service (see Figure 1) showed that most of the diagnoses were consistent. Although diagnoses are to some extent subjective, the advantage of the system is that the GP can compare his own choices with the diagnoses and advices from the pulmonologist. We believe that this internet-based consultation in the long run might improve skills in the management of OADs.

Van den Bemt et al. ${ }^{23}$ presented a service for COPD patients and concluded that it was not clinically effective. However, their population consisted of already-diagnosed COPD patients, and all patients had performed spirometry previously to inclusion, whereas we followed up both previously diagnosed and newly diagnosed patients. We speculate that the room for improvement in our population of a wide range of patients was higher, which might have contributed to the positive effect. Furthermore, internet is used for data exchange, and GPs receive the report from the pulmonologist mostly within 5 working days electronically in their patient information system, which makes the service user friendly. Next to that, the use of Internet and the trained lung function technicians make the service cost-effective. Direct costs were covered by reimbursement for the spirometry in primary care, including the involvement of the pulmonologist.

Generalisability. Our asthma patients differed from COPD patients, whereas the characteristics of overlap syndrome patients fell between asthma and COPD patients. This was also described by Postma et al. ${ }^{24}$ who showed that asthma patients are younger, more frequently female and have less frequently a history of smoking. Miravitlles et al. ${ }^{25}$ showed the same pattern of patient characteristics in their primary care population, although the proportion of male patients in their overlap syndrome population was much lower than in the AC population (Miravitlles: $26 \%$, AC service: $49 \%$ ). Characteristics of our asthma patients ( $\geqslant 16$ years) were comparable with asthmatics from the INSPIRE study (AC service: male, 38\%; mean age, $46 \pm 17$ years; current smokers, $21 \%$. INSPIRE: male $35 \%$; mean age, $45 \pm 17$ years; current smokers, 21\%).

When considering overlap syndrome as a subtype of COPD, the prevalence of overlap syndrome in our COPD population was $28 \%$, which is comparable to the prevalence found by Ställberg et al. ${ }^{26}$ (25\%) but higher than the prevalence reported by Postma et al.



Figure 2. Distribution of COPD patients at baseline ( $n$ (total) $=2,004$ ) according to the new GOLD classification of airflow limitation. Apparent is the large proportion of patients at risk: $22 \%$ of the COPD patients were classified as GOLD D. GOLD D patients have a high risk of exacerbations combined with a high burden of disease. 
Table 3. Longitudinal differences in lung function, exacerbations, health status and asthma control of patients assessed at baseline and after 3 months (range: $2-4$ months, $n$ total $=740$ )

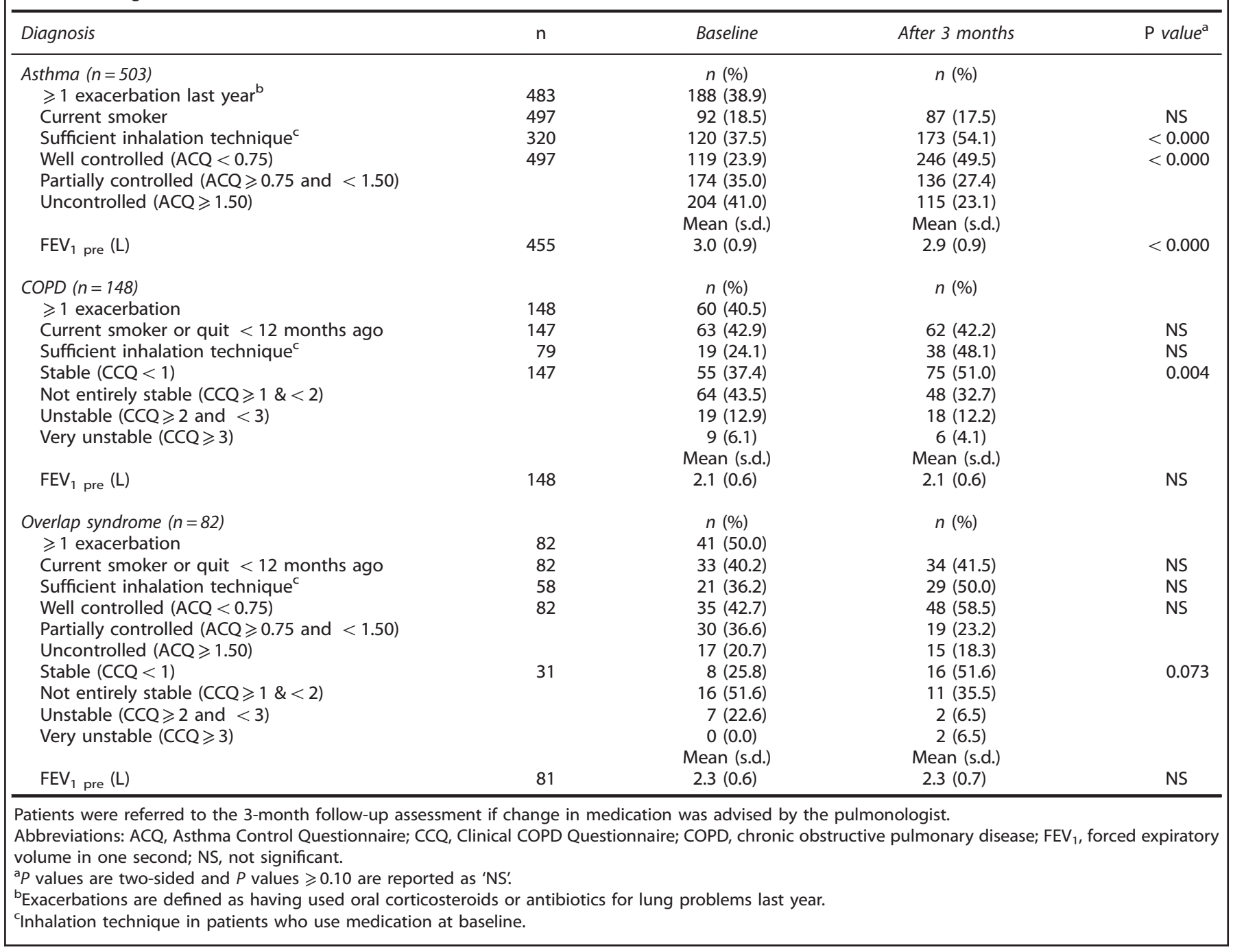

$(13-20 \%) .{ }^{24}$ Our overlap patients have more frequent exacerbations compared with the asthma and COPD patients, which indicate that these patients are more at risk for future exacerbations. This high risk was confirmed in other studies. ${ }^{24,27,28}$ Although these patients are more at risk, at baseline only the $C C Q$ scores reflect this poor health status (CCQ $\geqslant 3$ : COPD, 8\%; overlap syndrome, $10 \%$ ). Overlap patients were assessed by using the ACQ and the CCQ, because these questionnaires were part of the regular assessment in the AC collaboration service. However, no validated measurements are available to assess the health status and disease control in overlap patients. COPD patients in the $A C$ service were distributed according to the GOLD guidelines using CCQ cutoff value of $>1$ (A: $28 \%, B: 40 \%, C: 8 \%$ and D: $24 \%)$. Lange et al. ${ }^{29}$ distributed 6,628 Danish COPD patients using the modified Medical Research Council and found another distribution (A: $77 \%, B: 14 \%, C: 4 \%$ and D: $4 \%$ ). Apart from the difference in symptom assessment by using the CCQ instead of the modified Medical Research Council, our COPD sample of primary caretreated patients is obviously more at risk and has more symptoms than the Danish general population.

Reversibility. Only $17 \%$ of our asthma patients had a positive bronchodilator test (BDT) response. ${ }^{2}$ In asthma patients with good

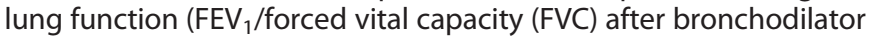

$\geqslant 90 \%$ ), the proportion of patients with a positive BDT was $5 \%$, whereas in asthma patients with very poor lung function $\left(\mathrm{FEV}_{1} / \mathrm{FVC}\right.$ post bronchodilator $<70 \%$ ), this proportion was $40 \%$. Others have also shown that reversibility in asthmatic patients depends on the severity of asthma as measured by the impairment in lung function. ${ }^{30}$ Although COPD is considered to be a nonreversible obstructive lung disease, $11 \%$ of our COPD patients had a BDT response, and the average reversibility was $6 \%$. In the UPLIFT study, 50\% of the COPD patients showed significant reversibility. ${ }^{31}$ Obviously, real-life COPD populations differ from selected populations, as confirmed by Kruis et al. ${ }^{32}$ Bronchodilator response was more prevalent in COPD patients with severe disease. ${ }^{24}$ The highest proportion of patients with positive BDT response was seen in the overlap syndrome patients (35\%), which is consistent with the GOLD and Global Initiative for Asthma recommendations. $^{33}$

Risk factors. The proportion of smoking COPD and overlap syndrome patients (COPD: 50\%, overlap syndrome: 45\%) was much higher than in the Dutch population, which is $27 \%$, and also higher than the COPD population presented by Warnier et al. ${ }^{34}$ (37\%). Our definition of smokers might have contributed to the higher proportion, because we considered quitters $<12$ months ago as current smokers. The AC service does not provide any 
Table 4. Longitudinal differences in lung function, exacerbations, health status and asthma control of patients referred by their GP to single or yearly follow-up assessment after 12 months (range 10-14 months, $n$ total $=991$ ). Patients in this table were not assessed after 3 months

\begin{tabular}{|c|c|c|c|c|}
\hline Diagnosis & $\mathrm{n}$ & Baseline & After 12 months & $\mathrm{P}$ value $\mathrm{a}^{\mathrm{a}}$ \\
\hline Asthma $(n=598)$ & & $n(\%)$ & $n(\%)$ & \\
\hline$\geqslant 1$ exacerbation $^{b}$ & 572 & $200(35.0)$ & $144(25.2)$ & $<0.000$ \\
\hline Current smokers or quit $<12$ months ago & 595 & $88(14.8)$ & $81(13.6)$ & NS \\
\hline Sufficient inhalation technique ${ }^{c}$ & 471 & $185(39.3)$ & $251(53.3)$ & $<0.000$ \\
\hline Well controlled (ACQ < 0.75) & 591 & $377(63.8)$ & $383(64.8)$ & NS \\
\hline Partially controlled $(A C Q \geqslant 0.75$ and $<1.50$ ) & & $119(20.1)$ & $123(20.8)$ & \\
\hline \multirow{2}{*}{\multicolumn{2}{|c|}{ Uncontrolled $(A C Q \geqslant 1.50)$}} & $95(16.1)$ & $85(14.4)$ & \\
\hline & & Mean (s.d.) & Mean (s.d.) & \\
\hline $\mathrm{FEV}_{1}$ pre $(\mathrm{L})$ & 596 & $3.1(0.9)$ & $3.0(0.9)$ & $<0.000$ \\
\hline $\operatorname{COPD}(n=245)$ & & $n(\%)$ & $n(\%)$ & \\
\hline$\geqslant 1$ exacerbation $^{\mathrm{b}}$ & 244 & $85(34.8)$ & $62(25.4)$ & 0.010 \\
\hline Current smokers or quit $<12$ months ago & 243 & $109(44.9)$ & $99(40.7)$ & 0.017 \\
\hline Sufficient inhalation technique ${ }^{c}$ & 177 & $59(33.3)$ & $78(44.1)$ & 0.034 \\
\hline Stable $(C C Q<1)$ & 243 & $128(52.7)$ & $136(56.0)$ & NS \\
\hline Not entirely stable $(\mathrm{CCQ} \geqslant 1$ and $<2)$ & & $79(32.5)$ & $74(30.5)$ & \\
\hline Unstable $(C C Q \geqslant 2 \&<3)$ & & $23(9.5)$ & $24(9.9)$ & \\
\hline \multirow[t]{2}{*}{ Very unstable $(C C Q \geqslant 3)$} & & $13(5.3)$ & $9(3.7)$ & \\
\hline & & Mean (s.d.) & Mean (s.d.) & \\
\hline $\mathrm{FEV}_{1}$ pre $(\mathrm{L})$ & 244 & $2.2(0.7)$ & $2.1(0.6)$ & $<0.000$ \\
\hline Overlap syndrome $(n=88)$ & & $n(\%)$ & $n(\%)$ & \\
\hline$\geqslant 1$ exacerbation $^{\mathrm{b}}$ & 88 & $34(38.6)$ & $25(28.4)$ & NS \\
\hline Current smokers or quit $<12$ months ago & 88 & $38(43.2)$ & $34(38.6)$ & 0.094 \\
\hline Sufficient inhalation technique ${ }^{c}$ & 66 & $24(36.4)$ & $28(42.4)$ & NS \\
\hline Well controlled $(\mathrm{ACQ}<0.75)$ & 87 & $37(42.5)$ & $48(55.2)$ & 0.032 \\
\hline Partially controlled (ACQ $\geqslant 0.75$ and $<1.50$ ) & & $25(28.7)$ & $21(24.1)$ & \\
\hline Uncontrolled $(A C Q \geqslant 1.50)$ & & $25(28.7)$ & $18(20.7)$ & \\
\hline Stable $(C C Q<1)$ & 65 & $24(36.9)$ & $30(46.2)$ & 0.027 \\
\hline Not entirely stable $(C C Q \geqslant 1 \&<2)$ & & $27(41.5)$ & $26(40.0)$ & \\
\hline Unstable $(C C Q \geqslant 2$ and $<3)$ & & $7(10.8)$ & $7(10.8)$ & \\
\hline \multirow[t]{2}{*}{ Very unstable $(C C Q \geqslant 3)$} & & $7(10.8)$ & $2(3.1)$ & \\
\hline & & Mean (s.d.) & Mean (s.d.) & \\
\hline $\mathrm{FEV}_{1}$ pre $(\mathrm{L})$ & 88 & $2.3(0.7)$ & $2.2(0.7)$ & $<0.000$ \\
\hline
\end{tabular}

cessation intervention but informs the GP if their patients are motivated to quit. The follow-up time of 12 months could not reveal the number of quitters ( $>12$ months) as a result of the possible intervention of the GP.

Like in other studies, ${ }^{35}$ many patients (64\%) showed an insufficient inhalation technique. Although the inhalation technique improved after $3(50 \%)$ and 12 months (47\%) of follow-up after our standard instruction as recommended in the Dutch guidelines, it is debatable whether this instruction is sufficiently effective. Further research on effective instruction seems to be needed.

Strengths and limitations of this study

The strength of this study is the large population of primary care OAD patients in real life and the strict protocol used to assess these patients. A limitation is that the AC service was not established for scientific reasons, resulting in limited follow-up results, and data could not be compared with a control group. ${ }^{36}$ Therefore, we cannot rule out that results might have been affected by regression to the mean, although regression to the mean (measured by $1-\rho$ ) is small; ${ }^{37}$ see Supplementary 2 . We also do not have data on mortality; however, on the basis of national mortality data, we assume that $1.8 \%$ of the COPD patients have died in 1 year. Leivseth et al. ${ }^{38}$ showed that there are no large differences in mortality rates between GOLD A, B, C and D. Therefore, we assume that missed mortality rates hardly affected our COPD follow-up results.

Implications for future research, policy and practice

Relatively simple support for GPs in diagnosing and managing patients with a chronic disease by specialists might result in improved outcomes for these patients in the community. Principles of the AC service might also be suitable in other chronic diseases. The large electronic database from the $A C$ service provides unique opportunities for further research in primary care patients with OADs.

\section{Conclusion}

The AC service is feasible, effective and efficient in supporting GPs to diagnose and manage asthma, COPD and overlap syndrome patients. The service stimulates cooperation between primary and secondary care, and delivers support to patients locally which is important in rural areas.

\section{ACKNOWLEDGEMENTS}

We thank the Northern General Practitioners Laboratory Groningen (LabNoord currently Certe Laboratories) for giving us the opportunity to realise the AC service. 


\section{CONTRIBUTIONS}

All authors have contributed to writing and revising the manuscript.

\section{COMPETING INTERESTS}

RAR is a member of the advisory board of Certe Laboratories. MGP-W is the director of Certe Laboratories. TvdM is a member of the board of trustees of Certe Laboratories. JWHK is an Associate editor of npj Primary Care Respiratory Medicine, but was not involved in the editorial review of, nor the decision to publish, this article. The other authors declare no conflict of interest.

\section{FUNDING}

Funding was received from the University Medical Center Groningen.

\section{REFERENCES}

1 World Health Organization. Burden of COPD, 2012; Available at http://www.who. int/respiratory/copd/burden/en/index.html. Accessed 29 June 2012.

2 Global Initiative for Asthma. Pocket guide for asthma management and prevention, 2012; Available at http://www.ginasthma.org/.

3 Izquierdo JL, Martin A, de Lucas P, Rodriguez-Gonzalez-Moro JM, Almonacid C, Paravisini A. Misdiagnosis of patients receiving inhaled therapies in primary care. Int J Chron Obstruct Pulmon Dis 2010; 5: 241-249.

4 Hill K, Goldstein RS, Guyatt GH, Blouin M, Tan WC, Davis LL et al. Prevalence and underdiagnosis of chronic obstructive pulmonary disease among patients at risk in primary care. CMAJ 2010; 182: 673-678.

5 Pakhale S, Sumner A, Coyle D, Vandemheen K, Aaron S. (Correcting) misdiagnoses of asthma: a cost effectiveness analysis. BMC Pulm Med 2011; 11: 27-2466-11-27.

6 Price DB, Yawn BP, Jones RCM. Improving the differential diagnosis of chronic obstructive pulmonary disease in primary care. Mayo Clin Proc 2010; 85: 1122-1129.

7 Schirnhofer L, Lamprecht B, Firlei N, Kaiser B, Buist AS, Halbert RJ et al. Using targeted spirometry to reduce non-diagnosed chronic obstructive pulmonary disease. Respiration 2011; 81: 476-482.

8 The Dutch College of General Practitioners. Astma bij kinderen. 2014; Available at https://www.nhg.org/standaarden/samenvatting/astma-bij-kinderen. Accessed 11 February 2014.

9 The Dutch College of General Practitioners. Astma bij volwassenen, 2007; Available at https://www.nhg.org/standaarden/samenvatting/astma-bij-volwassenen. Accessed 11 February 2014.

10 The Dutch College of General Practitioners. COPD2007; Available at https://www. nhg.org/standaarden/samenvatting/copd. Accessed 11 February 2014.

11 Kruis AL, Smidt N, Assendelft WJ, Gussekloo J, Boland MR, Rutten-van Molken M et al. Cochrane corner: is integrated disease management for patients with COPD effective? Thorax 2014; 69: 1053-1055.

12 Chavannes NH, Grijsen M, van den Akker M, Schepers H, Nijdam M, Tiep B et al. Integrated disease management improves one-year quality of life in primary care COPD patients: a controlled clinical trial. Prim Care Respir J 2009; 18: 171-176.

13 Bonavia M, Averame G, Canonica W, Cricelli C, Fogliani V, Grassi C et al. Feasibility and validation of telespirometry in general practice: The Italian 'Alliance' study. Respir Med 2009; 103: 1732-1737.

14 Riemersma R, Meijer R, Kerstjens H, Tsiligianni I, Postma D, Molen Tvd. New developments in the treatment, diagnosing, and management of asthma in general practice. Drukkerij 1984: Appingedam, The Netherlands, 2010

15 van der Molen T, Willemse BW, Schokker S, ten Hacken NH, Postma DS, Juniper EF. Development, validity and responsiveness of the Clinical COPD Questionnaire. Health Qual Life Outcomes 2003; 1: 13.

16 American Thoracic Society/European Respiratory Society Task Force. Standards for the Diagnosis and Management of patients with COPD 2004; Available at http:// www.thoracic.org/clinical/copd-guidelines/resources/copddoc.pdf

17 Global Initiative for Chronic Obstructive Lung Disease (GOLD). Global stategy for the diagnosis, management, and prevention of COPD. 2013; Available at http:// www.goldcopd.org/.

18 Nationaal Kompas Volksgezondheid. Astma. 2014; Available at http://www.natio naalkompas.nl/gezondheid-en-ziekte/ziekten-en-aandoeningen/ademhalingswe gen/astma/. Accessed 23 May 2014.
19 Nationaal Kompas Volksgezondheid. Hoe vaak komt COPD voor en hoeveel mensen sterven eraan? 2013; Available at http://www.nationaalkompas.nl/ gezondheid-en-ziekte/ziekten-en-aandoeningen/ademhalingswegen/copd/omvang/. Accessed 13 February 2014.

20 Partridge $M$, van dM, Myrseth S, Busse W. Attitudes and actions of asthma patients on regular maintenance therapy: the INSPIRE study. BMC Pulm Med 2006; 6: 13.

21 Lucas A, Smeenk F, Smeele I, Brouwer T, van Schayck O. The validity of diagnostic support of an asthma/COPD service in primary care. Br J Gen Pract 2007; 57: 892-896.

22 Lucas AE, Smeenk FJ, van den Borne BE, Smeele IJ, van Schayck CP. Diagnostic assessments of spirometry and medical history data by respiratory specialists supporting primary care: are they reliable? Prim Care Respir J 2009; 18: 177-184.

23 van den Bemt L, Schermer TR, Smeele IJ, Boonman-de Winter LJ, van Boxem T, Denis J et al. An expert-supported monitoring system for patients with chronic obstructive pulmonary disease in general practice: results of a cluster randomised controlled trial. Med J Aust 2009; 191: 249-254.

24 Postma DS, Reddel HK, ten Hacken NHT, van den Berge M. Asthma and chronic obstructive pulmonary disease: similarities and differences. Clin Chest Med 2014; 35: 143-156.

25 Miravitlles M, Andreu I, Romero Y, Sitjar S, Altes A, Anton E. Difficulties in differential diagnosis of COPD and asthma in primary care. Br J Gen Pract 2012; 62: e68-e75.

26 Stallberg B, Janson C, Johansson G, Larsson K, Stratelis G, Telg G et al. Management, morbidity and mortality of COPD during an 11-year period: an observational retrospective epidemiological register study in Sweden (PATHOS). Prim Care Respir J 2014; 23: 38-45.

27 Andersen H, Lampela P, Nevanlinna A, Saynajakangas O, Keistinen T. High hospital burden in overlap syndrome of asthma and COPD. Clin Respir J 2013; 7: 342-346.

28 Louie S, Zeki AA, Schivo M, Chan AL, Yoneda KY, Avdalovic M et al. The asthmachronic obstructive pulmonary disease overlap syndrome: pharmacotherapeutic considerations. Expert Rev Clin Pharmacol 2013; 6: 197-219.

29 Lange P, Marott JL, Vestbo J, Olsen KR, Ingebrigtsen TS, Dahl M et al. Prediction of the clinical course of chronic obstructive pulmonary disease, using the new GOLD classification: a study of the general population. Am J Respir Crit Care Med 2012; 186: $975-981$.

30 Yancey SW, Ortega HG. Retrospective characterization of airway reversibility in patients with asthma responsive to bronchodilators. Curr Med Res Opin 2007; 23: 3205-3207.

31 Hanania NA, Sharafkhaneh A, Celli B, Decramer M, Lystig T, Kesten S et al. Acute bronchodilator responsiveness and health outcomes in COPD patients in the UPLIFT trial. Respir Res 2011; 12: 6-9921-12-6.

32 Kruis AL, van Schayck OC, in't Veen JC, van der Molen T, Chavannes NH. Successful patient self-management of COPD requires hands-on guidance. Lancet Respir Med 2013; 1: 670-672.

33 Global Initiative for Asthma and Global Initiative for COPD. Asthma COPD and Asthma-COPD Overlap Syndrome (ACOS), 2014; Available at http://www. ginasthma.organd http://www.goldcopd.org.

34 Warnier MJ, van Riet EE, Rutten FH, De Bruin ML, Sachs AP. Smoking cessation strategies in patients with COPD. Eur Respir J 2013; 41: 727-734.

35 Dekhuijzen PN, Bjermer L, Lavorini F, Ninane V, Molimard M, Haughney J. Guidance on handheld inhalers in asthma and COPD guidelines. Respir Med 2014; 108: 694-700.

36 Barnett AG, van der Pols JC, Dobson AJ. Regression to the mean: what it is and how to deal with it. Int J Epidemiol 2005; 34: 215-220.

37 Armitage P, Berry G, Matthews JNS. Regression to the mean. In: Brown A, Pattison F, Ord K (eds). Statistical Methods in Medical Research 4th edn Blackwell Publishing Company: Oxford, UK, 2002, pp 204-205, 206, 207.

38 Leivseth L, Brumpton BM, Nilsen TI, Mai XM, Johnsen R, Langhammer A. GOLD classifications and mortality in chronic obstructive pulmonary disease: the HUNT Study, Norway. Thorax 2013; 68: 914-921.

(i) $(-)$ This work is licensed under a Creative Commons AttributionBY NC ND NonCommercial-NoDerivatives 4.0 International License. The images or other third party material in this article are included in the article's Creative Commons license, unless indicated otherwise in the credit line; if the material is not included under the Creative Commons license, users will need to obtain permission from the license holder to reproduce the material. To view a copy of this license, visit http:// creativecommons.org/licenses/by-nc-nd/4.0/

Supplemental Information accompanies the paper on the npj Primary Care Respiratory Medicine website (http://www.nature.com/npjpcrm) 